Research Article

\title{
Experimental Research on the Specific Energy Consumption of Rock Breakage Using Different Waterjet-Assisted Cutting Heads
}

\author{
Hongxiang Jiang $\mathbb{D}^{1,2}$ and Deguang Meng $\mathbb{D}^{1}$ \\ ${ }^{1}$ College of Mechanical and Electrical Engineering, China University of Mining and Technology, Xuzhou 221116, China \\ ${ }^{2}$ Jiangsu Collaborative Innovation Center of Intelligent Mining Equipment, China University of Mining and Technology, \\ Xuzhou 221008, China \\ Correspondence should be addressed to Deguang Meng; ts17050110p2@cumt.edu.cn
}

Received 18 January 2018; Revised 23 February 2018; Accepted 27 February 2018; Published 29 April 2018

Academic Editor: Fernando Lusquiños

Copyright (C) 2018 Hongxiang Jiang and Deguang Meng. This is an open access article distributed under the Creative Commons Attribution License, which permits unrestricted use, distribution, and reproduction in any medium, provided the original work is properly cited.

\begin{abstract}
To investigate the specific energy consumption (SE) of rock breakage by cutting heads assisted by different types of waterjet and to identify optimal waterjet parameters and assistance types, rock cutting with and without waterjets was carried on a rock fragmentation test bed. SE is a comprehensive evaluation index and was developed according to the applied load on cutting head, and the SE under different cutting conditions was compared and analyzed. The results show that the SE of rock breakage without waterjet assistance increased with the increasing of rock compressive strength $\left(R_{\mathrm{CS}}\right)$ but that the limited drilling depth decreased. The effect of the waterjet pressure on the SE of rock breakage by the cutting head I was marked, and SE decreased by $30 \sim 40 \%$ when the ratio between $R_{\mathrm{CS}}$ and waterjet pressure was less than 1 . However, the function of the waterjet assistance was poor; therefore, a ratio of 1 could be used to distinguish the rock breakage effect of cutting head I. For cutting head II, the rock damage from the waterjet impact was limited due to the large waterjet standoff distance; thus the rock breakage performance of cutting head II was also limited. The waterjet impacting at the tip of the conical pick using cutting head III could enter into the cracks caused by the mechanical pick and fracture the rock. Therefore, the rock breakage performance of cutting head III was better than that of cutting head II.
\end{abstract}

\section{Introduction}

Coal and rock breakage is vital in underground mining, civil engineering, and so on [1-3]. Roadheaders are widely used in rock breakage, and the specific energy consumption of the cutting head is a key factor of rock breaking efficiency $[4,5]$. Reducing the specific energy consumption can enhance the rock breakage ability of cutting head, and the installation and geometry parameters of the conical pick have been widely investigated in experimental, theoretical, and numerical methods to decrease the pick load and specific energy consumption [6-9]. In coal mining and tunnel excavation, the temperature and pressure variations in underground mines were found to hasten the pick wearing process $[10,11]$, and the high-pressure waterjet technology has been used to reduce cutting force and extend pick service life [12-14]. However, the several high-pressure waterjet technologies can damage, fracture, weaken, and remove coal, rock, concrete, and other materials, including continuous waterjet [15] and pulsating waterjet [16]; thus it indicates that the rock breakage performance by mechanical tools can be improved if these highpressure waterjet technologies are used to assist rock cutting. Free-rolling cutters assisted by waterjets were used to study hard rock breakage [17], and the results show that the waterjet assistance could reduce the cutting forces more than $40 \%$ when four coherent waterjets were used in experiments. Rock breakage with waterjet assistance was summarized and concluded that further improvement of rock breakage performance can be achieved for short distances from the tool tip to the impact point [18], and plasticized material near the tip were efficiently removed. Li et al. [19] investigated the cutting performance of PDC cutters and found that adjusting the direction of the waterjets impacting on the rock surface at a medium pressure enhanced the rock cutting depth and 
optimal impact spacing. Ciccu et al. $[14,20]$ investigated the rock breaking performance of a PDC cutter with waterjet assistance and found a decrease in wear, an increase in excavation speed, and over $80 \%$ increase in rock cutting depth. Lu et al. [21] developed and studied a novel kind of the abrasive waterjet-assisted hard rock drilling technology, and the results show that when the drilling depth increased more than $63 \%$, the thrust force and torque reduced over $15 \%$ and $20 \%$, respectively. Liu et al. [22, 23] simulated the rock breakage by waterjet-assisted conical pick, and the results show that the rock fragmentation performance was better when the waterjet was placed through the pick center than that in front of the pick. Liu et al. [24] investigated the effects of the waterjet-nozzle position and waterjet pressure on the cutting torque and thrust force of scaled cutting head with conical picks and found that the waterjet could significantly help in reducing the cutting torque and thrust force.

Previous researches mainly focused on linear rock cutting by mechanical tools and waterjet-assisted mechanical tools, although the results have promoted the development of rock breaking using mechanical tools. Actually, the laboratory experiments of linear rock cutting by mechanical tools and waterjet-assisted mechanical tool cannot simulate the rock breakage of cutting head in underground mining actually; thus the previous research results for the design of revolving cutting head with waterjet assistance exist some boundedness. In addition, the previous research results of rock breakage by waterjet-assisted mechanical tool focused on cutting force, material removal rate, and so on, which were insufficient to estimate the rock breakage performance. Above all, few studies have involved the effect of rock properties on the rock breaking performance of waterjet-assisted rotary cutting heads; thus the verification of waterjet pressure in enhancing the rock breaking performance still lacks a basis.

Hence, a test bed for rock breakage by cutting head is put forward for simulating the rock breakage by cutting head actually, and high-pressure waterjets can be pumped into the center of conical picks or nozzles. Based on the developed test bed, the following topics were investigated: the comprehensive estimating index (specific energy consumption) was formulated according to the experimental cutting torque, pulling force, drilling depth, and rock removal volume; the effect of the waterjet/pick combination on the SE is investigated under different water pressure and $R_{\mathrm{CS}}$, whose aim is to confirm the preferable combined type; the rock breakage by a preferable waterjet-assisted cutting head is analyzed to ascertain the waterjet pressure suitable for specific $R_{\text {CS }}$ using a cutting head by multiple waterjet assistance; and the advantages and disadvantages of waterjet/pick combination were investigated to provide reference basis for waterjet assistance application in coal or rock cutting.

\section{Experiment Setup}

2.1. Test Bed for Rock Fragmentation. Figure 1 shows the test bed for rock breakage by cutting head with or without waterjet assistance $[25,26]$. The main drive system consists of those parts numbered 1 to 6 and 8 to 9 , which is used for rotation drive of the cutting head. In addition, the frequency converter can be used to adjust the rotation speed of the cutting head. In order to improve the power for rock breakage, a gearbox with a transmission ratio of 8 is installed between the cutting motor and cutting head. A rotary seal device is assembled in the output shaft, which is used to pump the high-pressure water into the cutting heads. Those parts numbered 11 to 18 constitute the assisted transmission system to reappear the drilling status of the roadheader in underground mining. The traction motion of the cutting head is controlled through a constant power system. When the rock strength changes in rock breakage, the pulling force and speed regulate with each other and guarantee the system running of the traction motor at the rated power range. The cutting torque and pulling force of the cutting head are measured by the torque and oil pressure sensors, respectively.

\subsection{Different Types of Waterjet/Pick Combinations for the} Cutting Head. Based on the general cutting head used with a roadheader [27-29], three waterjet-assisted cutting heads were developed using different waterjet/pick combinations (as shown in Figure 2): in cutting head I, the waterjet nozzle is integrated with the conical pick, as shown in Figure 2(a), and the direction of the waterjet velocity is parallel to the axis of the conical pick; in cutting head II, the nozzle is separate from the conical pick and ahead of the conical pick, as shown in Figure 2(b), and there is a distance between the waterjet impact point and the tip of the conical pick; and in cutting head III, the waterjet/pick combination is similar to cutting head II, but the distance between the waterjet impact point and the tip of the conical pick is almost equal to zero, as shown in Figure 2(c). Three cutting heads with high-pressure waterjet assistance corresponding to waterjet/pick combinations in Figure 2 are shown in Figure 3, which were used in the following experiments.

2.3. Artificial Rock Preparation. To reappear similar model experiments on rock breakage by mechanical tool, the failure patterns and characteristics of the similar materials should be similar to the prototype material as far as possible. Many kinds of rocks consisting of aggregate and cement are generally found in underground roadways such as shale, sandstone, and limestone. The structures and mechanical properties of aggregate and cement are similar with that of sand, cement, and gypsum. In similar model experiments, Portland cement \#42.5, grade B gypsum powder, and river sand are regard as the raw materials, which are used for producing the artificial rocks. The mechanical properties of the artificial rock with different mass ratios are listed in Table 1 , including density $(\rho)$, elasticity modulus $(E)$, rock comprehensive strength $\left(R_{\mathrm{CS}}\right)$, brazil tensile strength $\left(B_{\mathrm{TS}}\right)$, and Poisson's ratio $(v)$. Uniaxial compression tests reveal that the failure patterns of the artificial rock are similar to those of the actual rock.

\section{SE in Rock Fragmentation}

With a constant power hydraulic system, the cutting torque and pulling force versus time are difficult to estimate for the rock breakage performance of a cutting head under different 


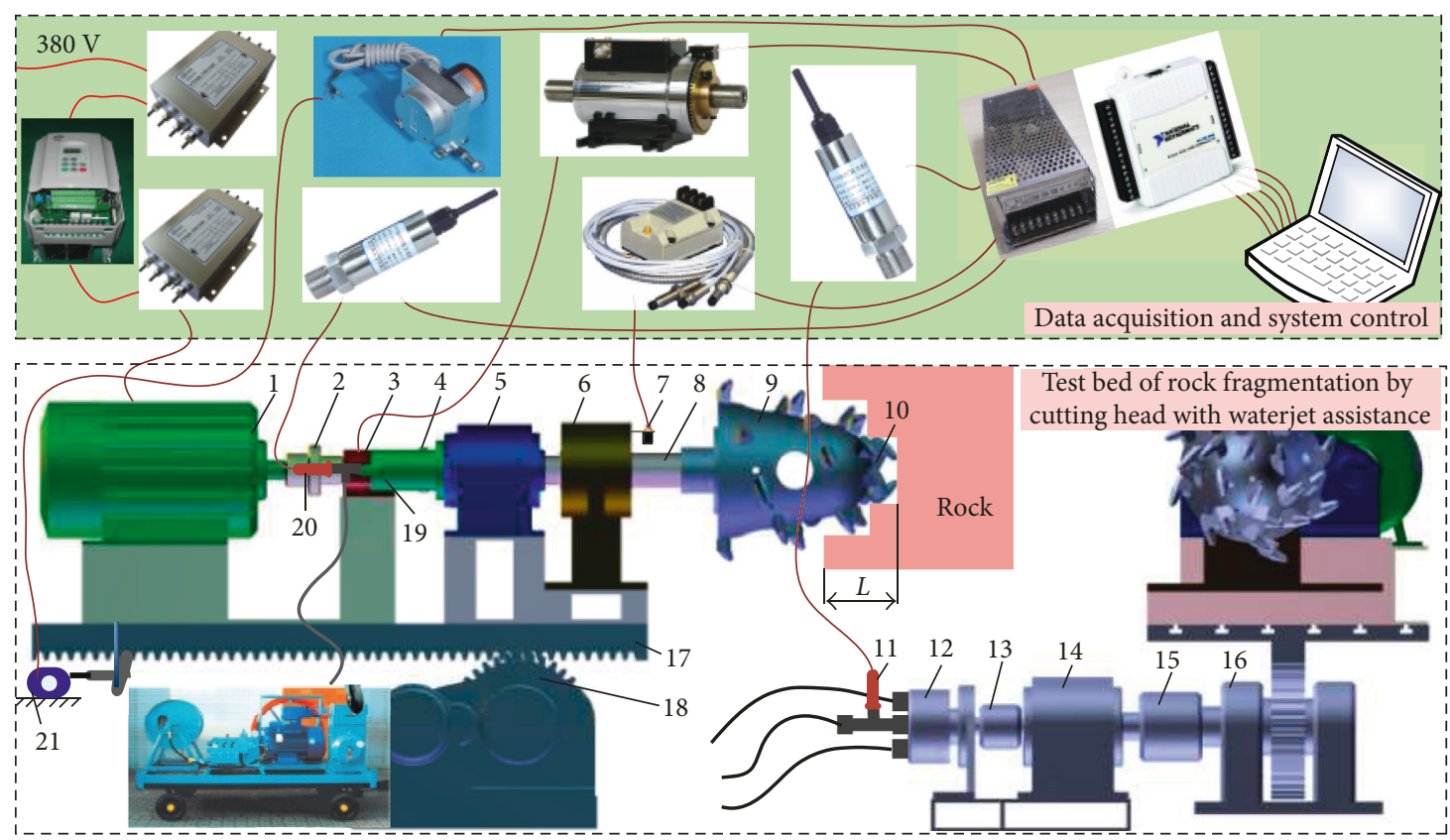

(a)

(b)

Figure 1: Transmission system of the test bed for rock cutting. (a) Front view. (b) Lateral view. 1: cutting motor; 2: coupler I; 3: torque sensor; 4: coupler II; 5: gearbox I; 6: bearing block I; 7: eddy current sensor; 8: cutting shaft; 9: cutting head; 10: oil pressure sensor; 11: hydraulic motor; 12: coupler III; 13: gearbox II; 14: coupler IV; 15: bearing block II; 16: bearing block III; 17: traction platform; 18: driving gear; 19: seal device; 20: water pressure sensor; 21: displacement sensor.



(a)

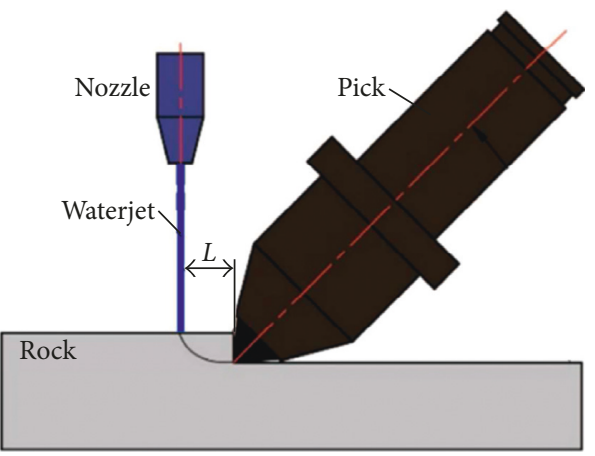

(b)

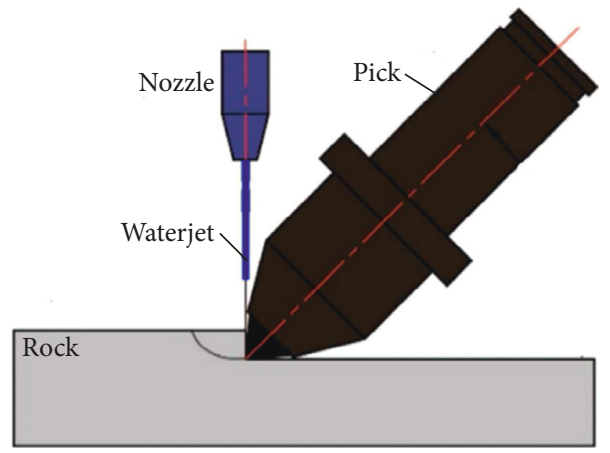

(c)

FIGURE 2: Different types of cutting heads with high-pressure waterjets. (a) Waterjet/pick combination for cutting head I. (b) Waterjet/pick combination for cutting head II. (c) Waterjet/pick combination for cutting head III. 


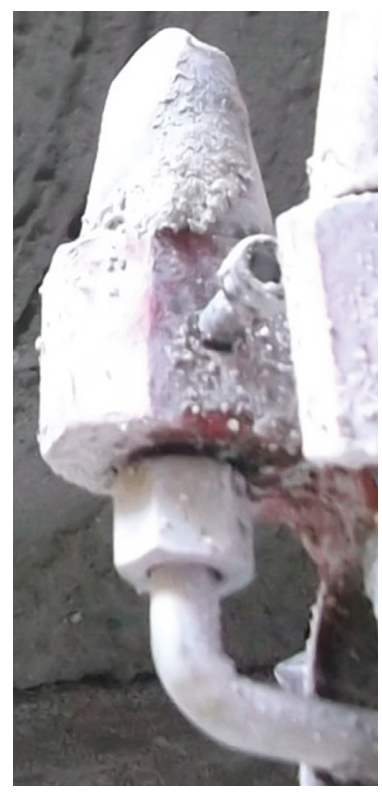

(a)

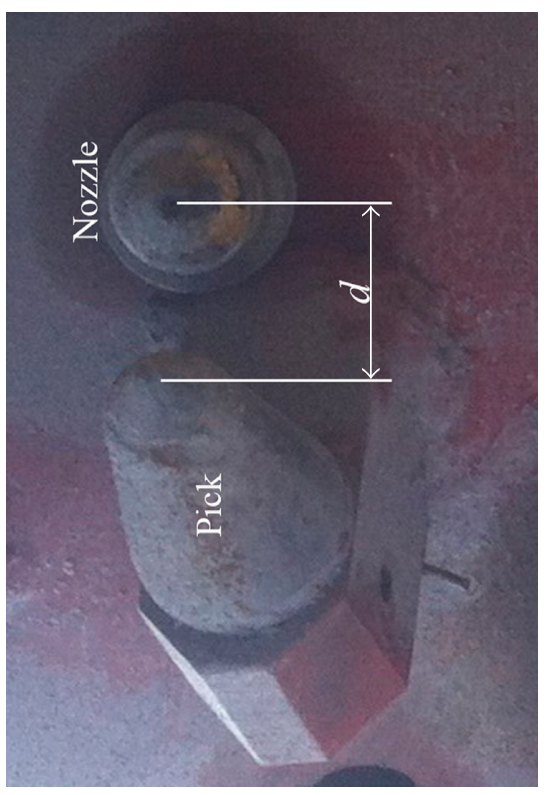

(b)

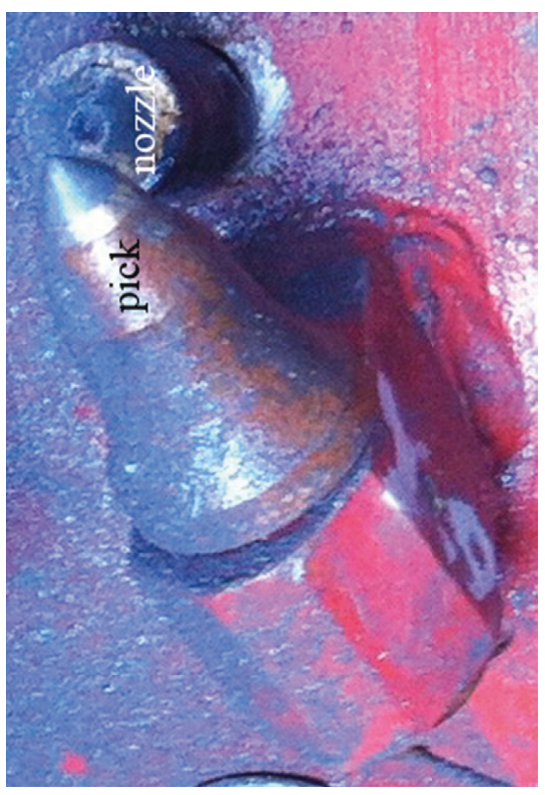

(c)

FIgURE 3: Experimental waterjet/pick combination corresponding to Figure 2. (a) Cutting head I. (b) Cutting head II. (c) Cutting head III.

TABLE 1: Mechanical properties of the artificial rock.

\begin{tabular}{lccccc}
\hline Number & $\rho\left(\mathrm{kg} / \mathrm{m}^{3}\right)$ & $E(\mathrm{GPa})$ & $R_{\mathrm{CS}}(\mathrm{MPa})$ & $B_{\mathrm{TS}}(\mathrm{MPa})$ & $v$ \\
\hline 1 & 2387 & $4.4 \pm 0.1$ & $15.2 \pm 0.2$ & $1.2 \pm 0.03$ & 0.23 \\
2 & 2436 & $7.8 \pm 0.1$ & $19.7 \pm 0.3$ & $2.1 \pm 0.04$ & 0.19 \\
3 & 2472 & $12.9 \pm 0.2$ & $23.6 \pm 0.3$ & $2.5 \pm 0.06$ & 0.22 \\
4 & 2548 & $15.2 \pm 0.5$ & $28.4 \pm 0.4$ & $2.7 \pm 0.10$ & 0.21 \\
\hline
\end{tabular}

cutting conditions; therefore, it is necessary to set up an effective index to evaluate the rock cutting performance. The cutting torque and pulling force could reflect the load of the cutting head at the same drilling depth; thus, the characteristic indexes of cutting torque or pulling force all depend on these loads versus the drilling depth. The cutting torque and pulling force versus drilling depth plots are shown in Figures 4 and 5, which show that the cutting torque and pulling force of all the simulations increase with increasing drilling depth. However, these parameters increase relatively uniformly due to the constant power hydraulic system used in the rock cutting test bed. The linear regression method was used to match the cutting torque and pulling force, and the slope of the regression line could be used to describe a characteristic index of the cutting torque or pulling force versus drilling depth. For example, the characteristic index of the cutting torque was equal to 4.79 in Figure 4 , and the characteristic index of the pulling force was equal to 0.134 in Figure 5. With the same rock type, a smaller characteristic index indicates a more efficient rock fragmentation ability of the cutting head under different conditions such as highpressure waterjet assistance.

The energy consumption of the rock fragmentation per unit volume is an important index for estimating the rock fragmentation performance of a cutting head comprehensively. In the rock cutting process, the energy consumption is

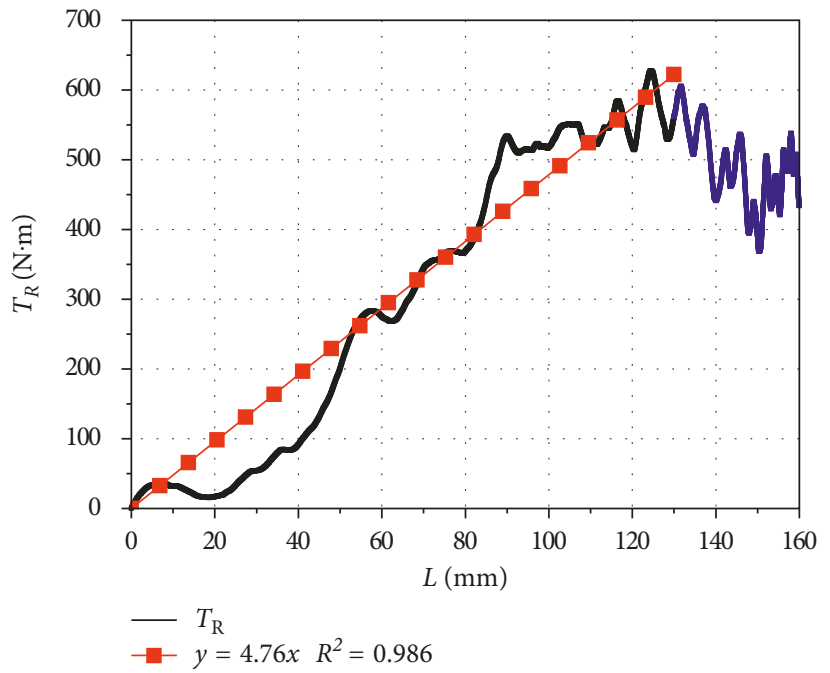

Figure 4: Cutting torque versus drilling depth.

created in two different ways: energy consumption due to the rotational motion of the cutting head and energy consumption due to the feed motion of the cutting head. Therefore, the SE can be expressed as follows:

$H_{\mathrm{w}}=H_{\mathrm{r}}+H_{\mathrm{h}}=\frac{W_{\mathrm{R}}+W_{\mathrm{H}}}{V}=\frac{P t+F_{\mathrm{q}} L}{m_{\mathrm{r}} / \rho_{\mathrm{r}}}=\frac{\rho_{\mathrm{r}}}{m_{\mathrm{r}}}\left(\frac{T_{\mathrm{R}} n t}{9550}+F_{\mathrm{q}} L\right)$.

Generally, the cutting torque and pulling force of the cutting head would change with the drilling time; thus, the energy consumption due to the rotational and feeding motions of the cutting head should be calculated through the integration of the cutting torque and pulling force versus time: 


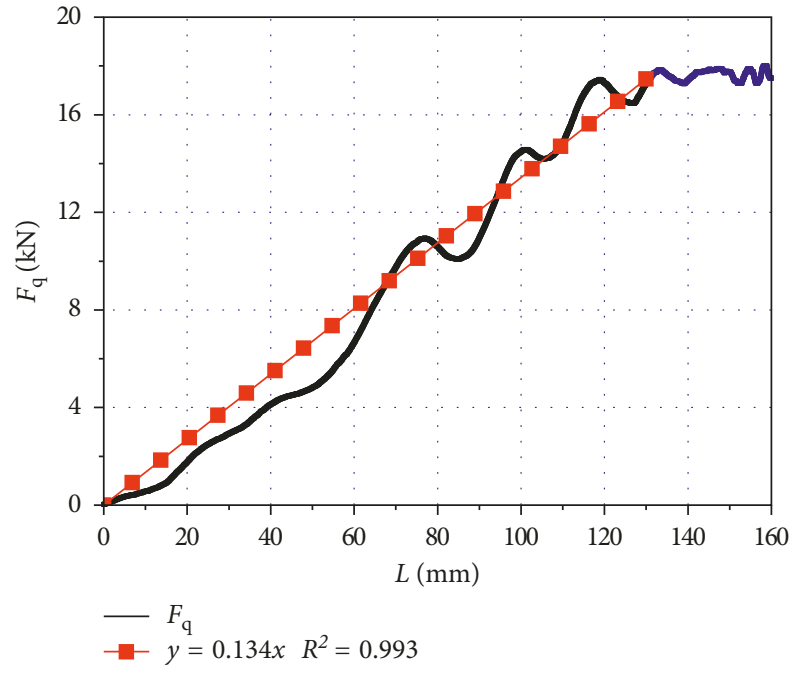

FIGURE 5: Pulling force versus drilling depth.

$$
\begin{aligned}
H_{\mathrm{w}} & =H_{\mathrm{r}}+H_{\mathrm{h}}=\frac{W_{\mathrm{R}}+W_{\mathrm{H}}}{V_{\mathrm{r}}}=\frac{P_{\mathrm{m}} t+F_{\mathrm{q}} L}{m_{\mathrm{r}} / \rho_{\mathrm{r}}} \\
& =\frac{\rho_{\mathrm{r}}}{m_{\mathrm{r}}}\left(\frac{\int_{0}^{t_{\mathrm{p}}} n_{\mathrm{c}} T_{\mathrm{R}}(t) \mathrm{d} t}{9550}+\frac{\int_{0}^{L_{\mathrm{p}}} F_{\mathrm{q}}(t) \mathrm{d} L}{1000}\right),
\end{aligned}
$$

where $H_{\mathrm{w}}$ is the total $\mathrm{SE}$ of the rock fragmentation, $\mathrm{kW} \cdot \mathrm{h} / \mathrm{m}^{3} ; H_{\mathrm{r}}$ is the SE due to the rotational motion of the cutting head, $\mathrm{kW} \cdot \mathrm{h} / \mathrm{m}^{3} ; H_{\mathrm{h}}$ is the SE due to the feeding motion of the cutting head, $\mathrm{kW} \cdot \mathrm{h} / \mathrm{m}^{3} ; W_{\mathrm{H}}$ is the energy consumption due to the feeding motion of the cutting head; $W_{\mathrm{R}}$ is the energy consumption due to the rotational motion of the cutting head; $V_{\mathrm{r}}$ is the volume of crushed rock; $P_{\mathrm{m}}$ is the motor power used in the rock cutting; $t$ is the duration of rock cutting; $m_{\mathrm{r}}$ is the mass of the crushed rock; $\rho_{\mathrm{r}}$ is the rock density; $n_{\mathrm{c}}$ is the rotation speed of the cutting head; $T_{\mathrm{R}}$ is the torque of the cutting head; $t_{\mathrm{p}}$ is the time when the load reaches the critical point; $F_{\mathrm{q}}$ is the pulling force of the cutting head; $L$ is the drilling depth of the cutting head; and $L_{\mathrm{p}}$ is the displacement when the load reaches the critical point.

According to (1) and (2), the cutting torque, rotation speed, pulling force, drilling depth, cutting time, mass, and volume of the crushed rock are necessary to measure. The rock density is a physical and mechanical property that is easily obtained. The sand filling method is used to measure the volume of crushed rock, and the other parameters are measured by a signal acquisition system.

\section{Results}

4.1. SE without Waterjet Assistance. SE is an important index for estimating rock fragmentation by a cutting head. Additionally, the drilling depth of a cutting head can also reflect the rock fragmentation by that cutting head with a constant power hydraulic system. According to (1) and (2), the three types of SE $\left(H_{\mathrm{w}}, H_{\mathrm{r}}\right.$, and $\left.H_{\mathrm{h}}\right)$ were calculated through the integration of the cutting torque versus time and pulling force versus drilling depth before the peak values. The SE and drilling depth of the rock fragmentation are listed in Table 2 and are shown in Figures 6 and 7 with different $R_{\mathrm{CS}}$.

Figure 6 shows that the three types of SE $\left(H_{\mathrm{w}}, H_{\mathrm{r}}\right.$, and $H_{\mathrm{h}}$ ) all increase with $R_{\mathrm{CS}}$. The reason for this relationship is that a greater $R_{\mathrm{CS}}$ results in a greater cutting torque and pulling force when the volume of crushed rock per time remains constant. By comparing the different SE $\left(H_{\mathrm{r}}\right.$ and $H_{\mathrm{h}}$ ), we found that $H_{\mathrm{r}}$ of the cutting head was greater than $H_{\mathrm{h}}$. Thus, $H_{\mathrm{w}}$ was mainly determined by rock fragmentation and rotational cutting. Based on the rock cutting theory, the rock is easily cut when $R_{\mathrm{CS}}$ is low; thus, the drilling depth of the cutting head approximately linearly decreased as $R_{\mathrm{CS}}$ increased. Theoretically, the shape of the cutting head could be regarded as a cone indenter, and the penetration depth decreases with an increase in the elastic material modulus according to the intact force model between the cone indenter and elastic material $[9,30]$. For rock material, high $R_{\mathrm{CS}}$ means a high elasticity modulus; thus, the drilling depth decreased with $R_{\mathrm{CS}}$ under a definite force.

4.2. SE of Cutting Head I. The waterjet/pick combination for cutting head I is shown in Figure 2(a), and the SE of cutting head I was investigated and compared with the cutting head without waterjet assistance. With a waterjet pressure of $22 \mathrm{MPa}$ for cutting head I, the three types of SE $\left(H_{\mathrm{w}}, H_{\mathrm{r}}\right.$, and $H_{\mathrm{h}}$ ) were calculated through the integration of the cutting torque versus time and the pulling force versus drilling depth, referenced against those values for the cutting head without waterjet assistance. The SE and drilling depth of the rock fragmentation by cutting head I are listed in Table 3 with various $R_{\mathrm{CS}}$.

The relationships between the three types of SE $\left(H_{\mathrm{w}}, H_{\mathrm{r}}\right.$, and $H_{\mathrm{h}}$ ) and the various $R_{\mathrm{CS}}$ are shown in Figure 8 . The decreased percentages of SE $\left(H_{\mathrm{w}}, H_{\mathrm{r}}\right.$, and $\left.H_{\mathrm{h}}\right)$ by using cutting head I with $22 \mathrm{MPa}$ high-pressure waterjets under different ratios of $R_{\mathrm{CS}}$ and waterjet pressure are shown in Figure 9. According to Figure $9, H_{\mathrm{w}}$ and $H_{\mathrm{r}}$ would reduce by $30 \sim 40 \%$ when the ratio between $R_{\mathrm{CS}}$ and the waterjet pressure was less than 1 . With high-pressure waterjet assistance, $H_{\mathrm{w}}$, $H_{\mathrm{r}}$, and $H_{\mathrm{h}}$ of cutting head I all increased with $R_{\mathrm{CS}}$, and their linear regression coefficients were equal to $0.91,0.99$, and 0.89 , respectively. The linear regression coefficients were all less than that of the cutting head without high-pressure waterjet assistance (0.94, 0.99, and 0.94 in Figure 6), indicating that the rock fragmentation mechanism of the cutting head I might be changed. The likely reason contributing to this degree of reduction in the linear association is that $H_{\mathrm{w}}$ was mainly determined by the rock fragmentation due to the rotational cutting; $H_{\mathrm{w}}$ of the cutting head had a clear criticality with high-pressure waterjet assistance. The SE would reduce by $30 \sim 40 \%$ when the ratio between $R_{\mathrm{CS}}$ and waterjet pressure was equal to 0.67 or 0.89 , but the reduction was only approximately $5 \% \sim 10 \%$ when the same ratio was equal to 1.07 or 1.29. Thus, a ratio of 1 could be used to distinguish the rock fragmentation performance of cutting head I.

With the same ultimate pulling force, the drilling depth and mass of the crushed rock can also reflect the effect of the high-pressure waterjet assistance on rock fragmentation. 
TABLE 2: Statistics of SE and $L_{\mathrm{p}}$ without waterjet assistance under various RCS.

\begin{tabular}{lcccccc}
\hline $\begin{array}{l}R_{\mathrm{CS}} \\
(\mathrm{MPa})\end{array}$ & $\begin{array}{c}H_{\mathrm{r}} \\
\left(\mathrm{kW} \cdot \mathrm{h} / \mathrm{m}^{3}\right)\end{array}$ & $\begin{array}{c}H_{\mathrm{h}} \\
\left(\mathrm{kW} \cdot \mathrm{h} / \mathrm{m}^{3}\right)\end{array}$ & $\begin{array}{c}H_{\mathrm{w}} \\
\left(\mathrm{kW} \cdot \mathrm{h} / \mathrm{m}^{3}\right)\end{array}$ & $\begin{array}{c}t_{\mathrm{p}} \\
(\mathrm{s})\end{array}$ & $\begin{array}{c}L_{\mathrm{p}} \\
(\mathrm{mm})\end{array}$ & $\begin{array}{c}m_{\mathrm{r}} \\
(\mathrm{kg})\end{array}$ \\
\hline 15.2 & 0.84 & 0.15 & 0.99 & 6.9 & 148 & 21.5 \\
19.7 & 0.97 & 0.17 & 1.14 & 6.0 & 130 & 17.4 \\
23.6 & 1.32 & 0.19 & 1.51 & 5.4 & 98 & 10.8 \\
28.4 & 1.47 & 0.23 & 1.70 & 4.8 & 83 & 8.1 \\
\hline
\end{tabular}

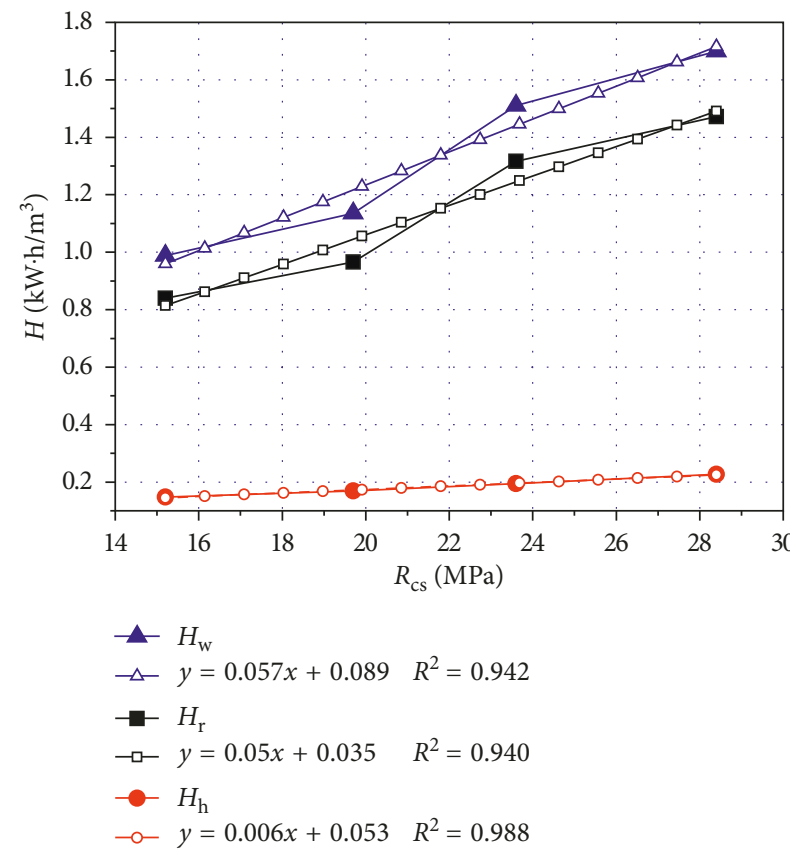

FIgURE 6: SE versus $R_{\mathrm{CS}}$ without waterjet assistance.

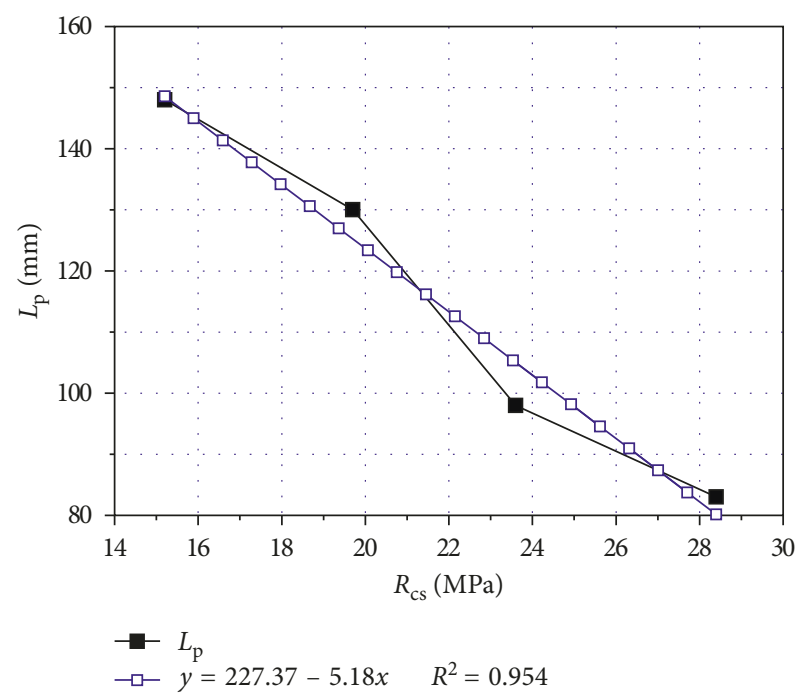

FIgURE 7: $L_{\mathrm{p}}$ versus $R_{\mathrm{CS}}$ without waterjet assistance.

The drilling depth of cutting head I versus $R_{\mathrm{CS}}$ is shown in Figure 10. The percentage of increase in the drilling depth and crushed rock mass of cutting head I compared with
TABLE 3: Statistics of SE and $L_{\mathrm{p}}$ with cutting head I under various $R_{\mathrm{CS}}$.

\begin{tabular}{lcccccc}
\hline $\begin{array}{l}R_{\mathrm{CS}} \\
(\mathrm{MPa})\end{array}$ & $\begin{array}{c}H_{\mathrm{r}} \\
\left(\mathrm{kW} \cdot \mathrm{h} / \mathrm{m}^{3}\right)\end{array}$ & $\begin{array}{c}H_{\mathrm{h}} \\
\left(\mathrm{kW} \cdot \mathrm{h} / \mathrm{m}^{3}\right)\end{array}$ & $\begin{array}{c}H_{\mathrm{w}} \\
\left(\mathrm{kW} \cdot \mathrm{h} / \mathrm{m}^{3}\right)\end{array}$ & $\begin{array}{c}t_{\mathrm{c}} \\
(\mathrm{s})\end{array}$ & $\begin{array}{c}L_{\mathrm{p}} \\
(\mathrm{mm})\end{array}$ & $\begin{array}{c}m_{\mathrm{rp}} \\
(\mathrm{kg})\end{array}$ \\
\hline 15.2 & 0.51 & 0.09 & 0.60 & 5.9 & 196 & 33.3 \\
19.7 & 0.63 & 0.13 & 0.76 & 5.3 & 146 & 21.2 \\
23.6 & 1.16 & 0.16 & 1.32 & 4.9 & 105 & 12.0 \\
28.4 & 1.44 & 0.20 & 1.64 & 4.3 & 88 & 8.75 \\
\hline
\end{tabular}

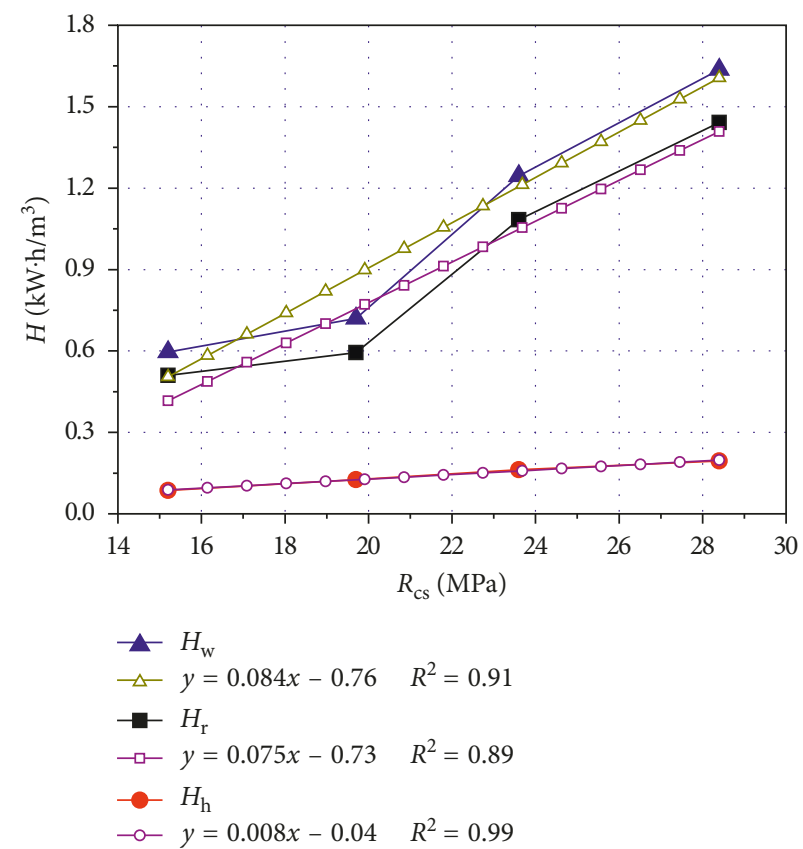

Figure 8: SE versus $R_{\mathrm{CS}}$ of cutting head I.

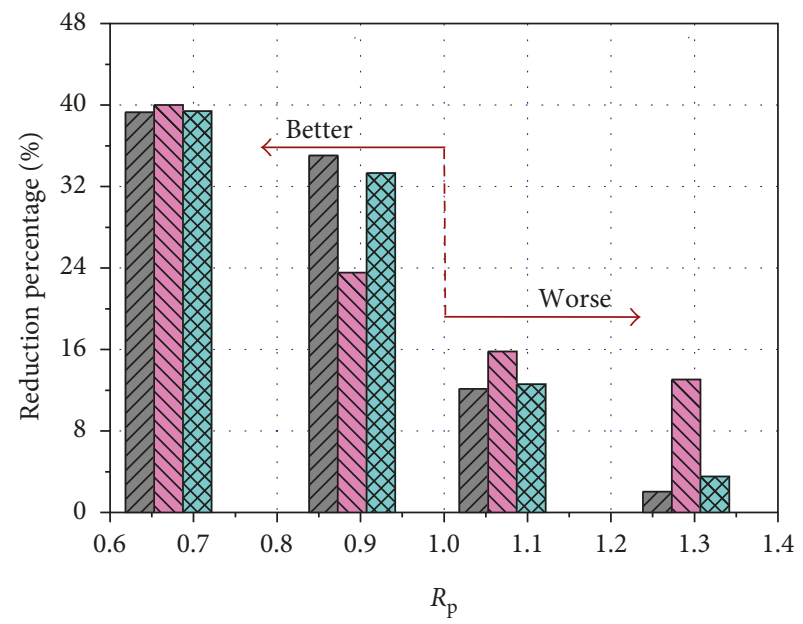

$H_{\mathrm{w}}$

VID $H_{\mathrm{r}}$

NIN $H_{\mathrm{h}}$

FIgUre 9: Percentages of the decrease in SE versus $R_{\mathrm{p}}$ of cutting head I. 


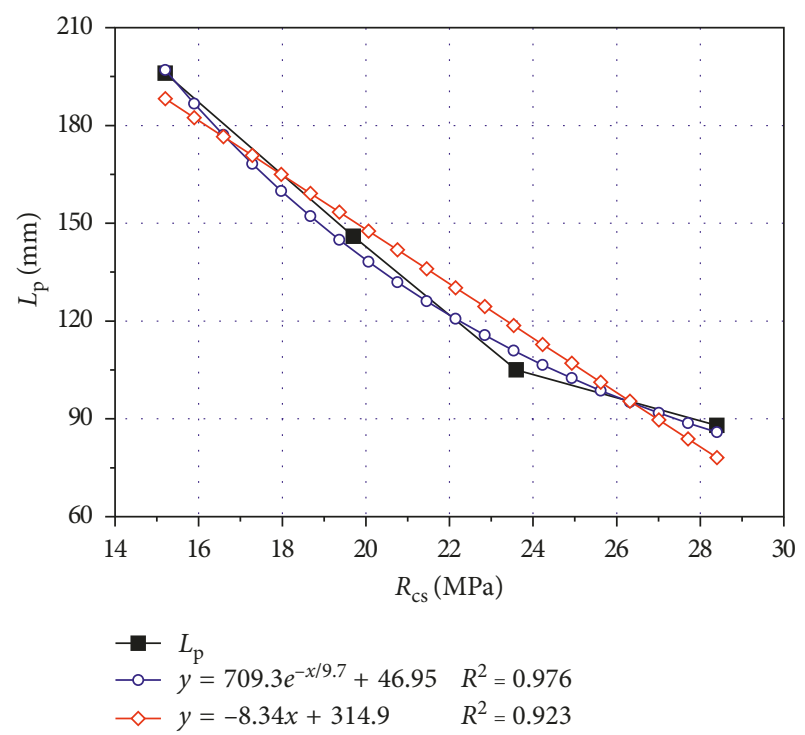

FIgURE 10: $L_{\mathrm{p}}$ versus $R_{\mathrm{CS}}$ of cutting head I.

those of the cutting head without high-pressure waterjet assistance are shown in Figure 11. The drilling depth of the cutting head without waterjet assistance was different than that of cutting head I, as shown in Figure 7; the drilling depth versus $R_{\mathrm{CS}}$ was more consistent with an exponential function. The percentage of increase in the drilling depth and crushed rock mass of cutting head I sharply decreased with the ratio between $R_{\mathrm{CS}}$ and waterjet pressure. When the ratio was equal to 0.67 , the drilling depth of cutting head I increased more than $30 \%$, and the crushed rock mass increased more than $55 \%$. When the ratio between $R_{\mathrm{CS}}$ and waterjet pressure was less than 1 , the fitting curves of the enhanced percentage of drilling depth and crushed rock mass of cutting head I all plateaued, suggesting that the assistance of the high-pressure waterjet action was not apparent.

4.3. SE of Cutting Heads II and III. The results of the three types of $\operatorname{SE}\left(H_{\mathrm{w}}, H_{\mathrm{r}}\right.$, and $\left.H_{\mathrm{h}}\right)$ and the drilling depth of cutting head II with $22 \mathrm{MPa}$ waterjets are listed in Table 4. $H_{\mathrm{w}}$ was $0.88 \mathrm{~kW} \cdot \mathrm{h} / \mathrm{m}^{3}$ and $1.06 \mathrm{~kW} \cdot \mathrm{h} / \mathrm{m}^{3}$, respectively, corresponding to $R_{\mathrm{CS}}$ of $15.2 \mathrm{MPa}$ and $19.7 \mathrm{MPa}$ and decrease of $11.1 \%$ and $7.0 \%$ compared with the cutting head without highpressure waterjet assistance. Moreover, their limited drilling depths were equal to $157 \mathrm{~mm}$ and $134 \mathrm{~mm}$, respectively, only increasing $7 \mathrm{~mm}$ and $4 \mathrm{~mm}$ compared with the cutting head without high-pressure waterjet assistance. This analysis indicated that the rock fragmentation ability of cutting head II with high-pressure waterjet assistance could not be improved when $R_{\mathrm{CS}}$ was less than the waterjet pressure.

The results of the three types of SE $\left(H_{\mathrm{w}}, H_{\mathrm{r}}\right.$, and $\left.H_{\mathrm{h}}\right)$ and drilling depth of cutting head III with $22 \mathrm{MPa}$ waterjets are listed in Table 5. $H_{\mathrm{w}}$ was equal to $0.69 \mathrm{~kW} \cdot \mathrm{h} / \mathrm{m}^{3}$ and $0.85 \mathrm{~kW} \cdot \mathrm{h} / \mathrm{m}^{3}$, respectively, corresponding to $R_{\mathrm{CS}}$ of $15.2 \mathrm{MPa}$ and $19.7 \mathrm{MPa}$ and decrease of $30.3 \%$ and $25.4 \%$ compared with the cutting head without high-pressure waterjet assistance. Moreover, the limited drilling depths of these experiments were equal to $175 \mathrm{~mm}$ and $144 \mathrm{~mm}$, respectively,

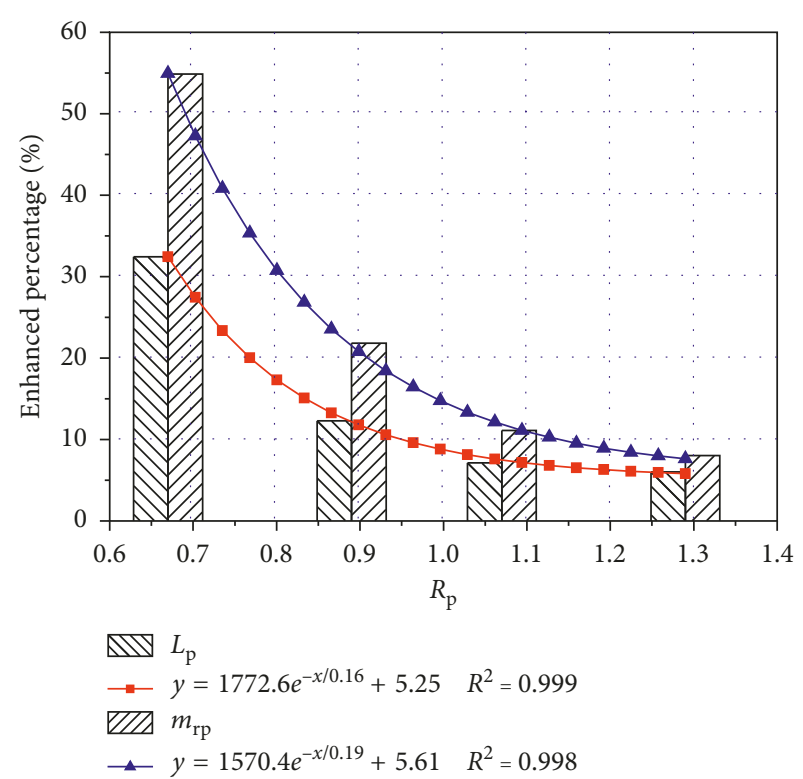

FIgURE 11: $L_{\mathrm{p}}$ and $m_{\mathrm{rp}}$ percentage increase versus $R_{\mathrm{p}}$ of cutting head I.

increasing only $27 \mathrm{~mm}$ and $14 \mathrm{~mm}$ compared with the cutting head without high-pressure waterjet assistance. The above analysis indicated that the rock fragmentation ability of cutting head III with high-pressure waterjet assistance clearly could be improved when $R_{\mathrm{CS}}$ was less than the waterjet pressure. Compared with cutting heads I and II, when the assisted waterjet pressure was larger than $R_{\mathrm{CS}}$, we found that the rock fragmentation ability of cutting head III was more effective than that of cutting head II with high-pressure waterjet assistance but less effective than that of cutting head I.

\section{Discussion}

The difference in the rock fragmentation ability with different cutting heads was related to several reasons. (a) Due to the small distance between the high-pressure waterjet nozzle and rock surface with cutting head I, the high-pressure waterjet could directly crush the rock due to water hammer action when the waterjet pressure was higher than $R_{\mathrm{CS}}$. Additionally, the apparent formation of cutting kerfs (as shown in Figure 12) by waterjet brought about the dramatic decrease in the cutting torque when $R_{\mathrm{CS}}$ was smaller than the waterjet pressure. (b) The waterjet could damage and weaken the rock strength when the waterjet pressure was less than $R_{\mathrm{CS}}$; thus, the cutting torque should theoretically decrease during rock fragmentation by cutting head I with the assistance of a $22 \mathrm{MPa}$ waterjet. However, the percentages of decrease in the three types of SE $\left(H_{\mathrm{w}}, H_{\mathrm{r}}\right.$, and $\left.H_{\mathrm{h}}\right)$ were all very small, possibly caused by the blunt waterjet pick tip (as shown in Figure 2(a)) in cutting head I.

According to the linear rock cutting experiments using a conical pick with high-pressure waterjet assistance, the cutting force could clearly decrease when the high-pressure waterjet was set before the conical pick as in the waterjet/pick combination for cutting head II, shown in Figure 2(b). Even if 
TABLE 4: Statistics of SE and $L_{\mathrm{p}}$ with cutting head II under various $R_{\mathrm{CS}}$.

\begin{tabular}{lccccccc}
\hline$R_{\mathrm{CS}}(\mathrm{MPa})$ & $H_{\mathrm{r}}\left(\mathrm{kW} \cdot \mathrm{h} / \mathrm{m}^{3}\right)$ & $H_{\mathrm{h}}\left(\mathrm{kW} \cdot \mathrm{h} / \mathrm{m}^{3}\right)$ & $H_{\mathrm{w}}\left(\mathrm{kW} \cdot \mathrm{h} / \mathrm{m}^{3}\right)$ & $t_{\mathrm{c}}(\mathrm{s})$ & $L_{\mathrm{p}}(\mathrm{mm})$ & $m_{\mathrm{rp}}(\mathrm{kg})$ & $R_{\mathrm{PH}}(\%)$ \\
\hline 15.2 & 0.75 & 0.13 & 0.88 & 6.7 & 157 & 23.6 \\
19.7 & 0.90 & 0.16 & 1.06 & 6.0 & 134 & $1.1 \%$ \\
\hline
\end{tabular}

TABle 5: Statistics of SE and $L_{\mathrm{p}}$ with cutting head III under different $R_{\mathrm{CS}}$.

\begin{tabular}{lccccccc}
\hline$R_{\mathrm{CS}}(\mathrm{MPa})$ & $H_{\mathrm{r}}\left(\mathrm{kW} \cdot \mathrm{h} / \mathrm{m}^{3}\right)$ & $H_{\mathrm{h}}\left(\mathrm{kW} \cdot \mathrm{h} / \mathrm{m}^{3}\right)$ & $H_{\mathrm{w}}\left(\mathrm{kW} \cdot \mathrm{h} / \mathrm{m}^{3}\right)$ & $t_{\mathrm{c}}(\mathrm{s})$ & $L_{\mathrm{p}}(\mathrm{mm})$ & $m_{\mathrm{rp}}(\mathrm{kg})$ & $R_{\mathrm{PH}}(\%)$ \\
\hline 15.2 & 0.58 & 0.11 & 0.69 & 6.3 & 175 & 28.0 & $30.3 \%$ \\
19.7 & 0.71 & 0.14 & 0.85 & 5.5 & 144 & 19.6 & $25.4 \%$ \\
\hline
\end{tabular}

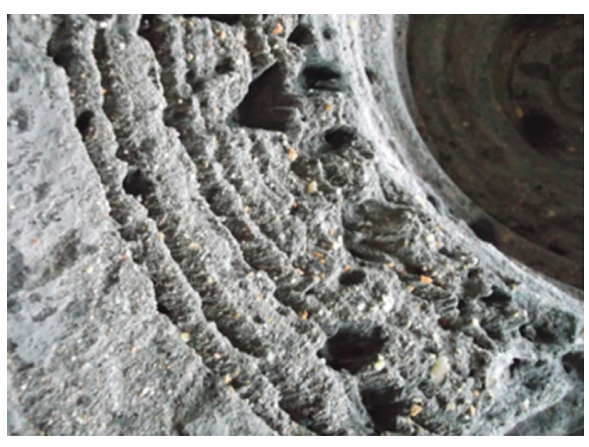

(a)

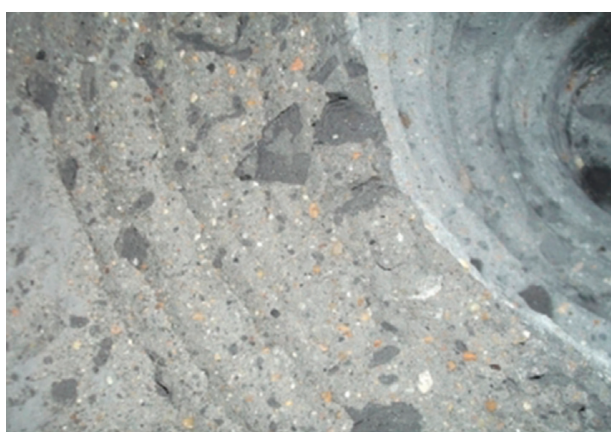

(b)

Figure 12: Rock kerfs using cutting head I with $22 \mathrm{MPa}$ waterjet assistance. (a) 15.2 MPa. (b) 19.7 MPa.

$R_{\mathrm{CS}}$ was lower than the waterjet pressure, the rock fragmentation performance of cutting head II assisted by high-pressure waterjets could not be markedly improved. Due to the selfstructure limitation of the cutting head, the standoff distances between the waterjet and the rock surface for cutting heads II and III were greater than that of the linear rock cutting experiments by conical pick with high-pressure waterjet assistance, and waterjet diffusion into the air also decreased the rock stresses by waterjet impact. The waterjet velocity field in the air was determined by using a fluid mechanics numerical simulation method [31, 32], when the nozzle diameter and shrinking angle were equal to $0.7 \mathrm{~mm}$ and $13^{\circ}$, respectively. The waterjet velocity distribution in the air is shown in Figure 12(a), and it indicated that the waterjet velocity from the nozzle outlet quickly attenuated. When the distance from the nozzle outlet was equal to $20 \mathrm{~mm}$, the waterjet velocity decreased from $210 \mathrm{~m} / \mathrm{s}$ to $125 \mathrm{~m} / \mathrm{s}$ as shown in Figure 13(a). In addition, the waterjet velocity declined laterally, as shown in Figure 13(b). Because the rock fragmentation ability of the waterjet impact was determined by the waterjet velocity, the rock fragmentation by waterjet impact decreased due to the distance between the nozzle outlet and rock surface in cutting head II. Under this condition, the stress caused by the waterjet impact was difficult to connect to the stress induced by the conical pick, and this is why the rock fragmentation performance of cutting head II was poor. The rock cutting surfaces from cutting head II with $22 \mathrm{MPa}$ waterjet assistance are shown in Figures 14(a) and 14 (b) when $R_{\mathrm{CS}}$ was $15.2 \mathrm{MPa}$ and 19.7 MPa, respectively. It was easily found that there was no obvious kerf in the rock surface because the rock fragmentation ability of the waterjet impact decreased at a waterjet standoff of $50 \mathrm{~mm}$.
According to the rock fragmentation performance of cutting head II, we found that waterjet-assisted rock cutting was ineffective when there was space between the waterjet impact point and the pick tip, verifying that it was difficult to improve the rock cutting performance by external waterjet assistance, as shown in Figure 2(b). However, when the $22 \mathrm{MPa}$ waterjet impact point was directly ahead of the conical pick tip (as shown in Figure 2(c)), the rock fragmentation ability of cutting head III could improve the rock cutting performance of rock with $R_{\mathrm{CS}}$ of $15.2 \mathrm{MPa}$ and $19.7 \mathrm{MPa}$, indicating that the hydraulic fracture mechanism was triggered using the waterjet/pick combination of cutting head III [33, 34]. Compared with the rock cutting surfaces created by using cutting heads II and III with $22 \mathrm{MPa}$ waterjet assistance (as shown in Figures 13 and 14, resp.), we found that there were several traces of rock debris avalanches in the cutting path when using cutting head III (as shown in Figure 15), but similar phenomena were rare when using cutting head II (as shown in Figure 14). Considering the waterjet/pick combination type in cutting head III, the rock fragmentation ability of the conical pick did not decrease, and its rock fragmentation ability was slightly worse than that of cutting head I when the waterjet pressure exceeded $R_{\mathrm{CS}}$.

\section{Conclusions}

Rock fragmentation experiments with or without waterjet assistance were carried on a custom-made rock cutting test bed, and the rock fragmentation performance of a cutting head under different cutting conditions was investigated, and the main conclusions are as follows: 




$\neg-$ Velocity in $x$ direction

(a)



$$
\begin{aligned}
& \neg-x=30 \mathrm{~mm} \\
& -\bigcirc x=40 \mathrm{~mm} \\
& \triangle \quad x=50 \mathrm{~mm}
\end{aligned}
$$

(b)

FIgURE 13: Waterjet velocity distribution in the air. (a) Central velocity of the waterjet. (b) Lateral waterjet velocity.

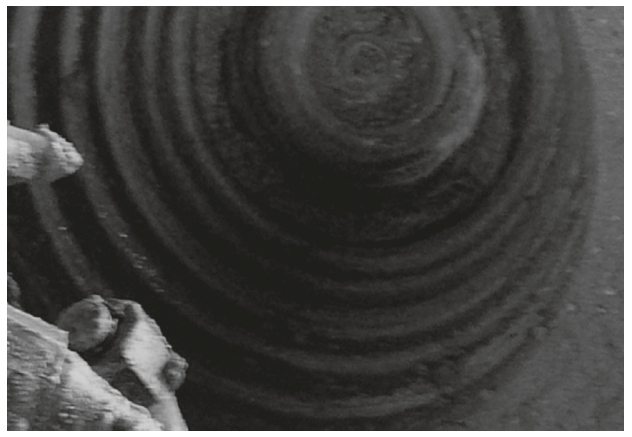

(a)

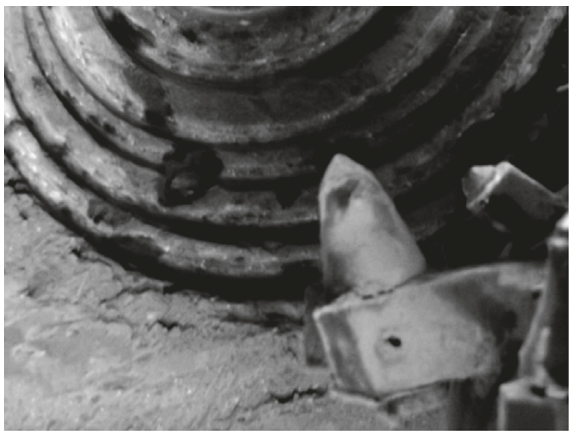

(b)

FIGURE 14: Rock surfaces using cutting head II with $22 \mathrm{MPa}$ waterjet assistance. (a) 15.2 MPa. (b) 19.7 MPa.



(a)

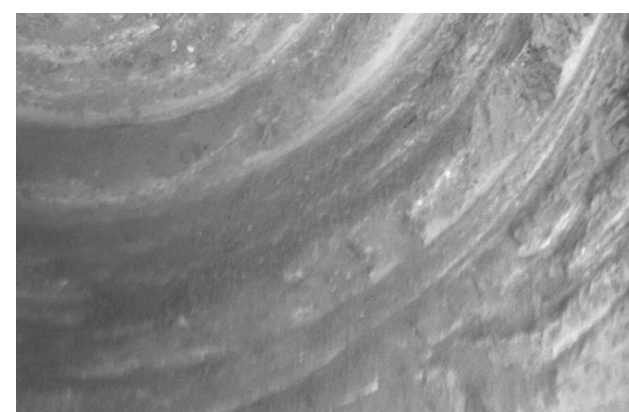

(b)

Figure 15: Rock surfaces created by using cutting head III with $22 \mathrm{MPa}$ waterjet assistance. (a) 15.2 MPa. (b) $19.7 \mathrm{MPa}$.

(1) The three types of SE $\left(H_{\mathrm{w}}, H_{\mathrm{r}}\right.$, and $\left.H_{\mathrm{h}}\right)$ all increased with $R_{\mathrm{CS}}$, but the limited drilling depth of the cutting head decreased as $R_{\mathrm{CS}}$ increased. In the rock cutting process, the SE due to the rotational motion of the cutting head was greater than that caused by the rotational motion of the cutting head; therefore, the total SE of the cutting head was determined by the rotational motion. 
(2) The SE due to the rotational motion of cutting head I was largely influenced by the waterjet pressure. Additionally, a clear demarcation point existed in the rock fragmentation performance of cutting head I. The SE would reduce by $30 \sim 40 \%$ when the ratio between $R_{\mathrm{CS}}$ and waterjet pressure was less than 1 , but the assisted action of the high-pressure waterjet was ineffective when the ratio exceeded 1 . Therefore, a ratio of 1 could be used to distinguish the effectiveness of the rock fragmentation by waterjet assistance.

(3) Due to the structural limitation of a cutting head, the external waterjet standoff distance (cutting head II) was greater than that of the linear rock cutting assisted by an external waterjet; therefore, the stress on the rock surface caused by the waterjet impact was limited because of the waterjet diffusion into the air, worsening the rock fragmentation performance by cutting head II. Although the rock fragmentation ability of the external waterjet impact was poor, the rock hydraulic fracture mechanism could be activated when the waterjet was shot from the conical pick tip (cutting head III), making the rock fragmentation performance of cutting head III better than that of cutting head II.

\section{Conflicts of Interest}

The authors declare that there are no conflicts of interest regarding the publication of this paper.

\section{Acknowledgments}

This research is supported by the Fundamental Research Funds for the Central Universities (2018QNB07) and the Priority Academic Program Development of Jiangsu Higher Education Institute of China.

\section{References}

[1] W. G. Shen, T. Zhao, G. B. Crosta, and F. Dai, "Analysis of impact-induced rock fragmentation using a discrete element approach," International Journal of Rock Mechanics and Mining Sciences, vol. 98, pp. 33-38, 2017.

[2] H. X. Jiang, Z. H. Liu, and K. D. Gao, "Numerical simulation on rock fragmentation by discontinuous water-jet using coupled SPH/FEA method," Powder Technology, vol. 312, pp. 248-259, 2017.

[3] Y. M. Xia, B. Guo, G. Q. Cong, X. H. Zhang, and G. Y. Zeng, "Numerical simulation of rock fragmentation induced by a single TBM disc cutter close to a side free surface," International Journal of Rock Mechanics and Mining Sciences, vol. 91, pp. 40-48, 2017.

[4] N. Bilgin, T. Dincer, H. Copur, and M. Erdogan, "Some geological and geotechnical factors affecting the performance of a roadheader in an inclined tunnel," Tunnelling and Underground Space Technology, vol. 19, no. 6, pp. 629-636, 2004.

[5] Z. H. Liu, C. L. Du, H. X. Jiang, and K. Liu, "Analysis of roadheader for breaking rock containing holes under confining pressures," Energies, vol. 10, no. 12, p. 1154, 2017.

[6] H. Copur, N. Bilgin, H. Tuncdemir, and C. Balci, "A set of indices based on indentation tests for assessment of rock cutting performance and rock properties," Journal of the
Southern African Institute of Mining and Metallurgy, vol. 103, no. 9, pp. 589-599, 2003.

[7] N. Bilgin, M. A. Demircin, H. Copur, C. Balci, H. Tuncdemir, and N. Akcim, "Dominant rock properties affecting the performance of conical picks and the comparison of some experimental and theoretical results," International Journal of Rock Mechanics and Mining Sciences, vol. 43, no. 1, pp. 139-156, 2006.

[8] R. H. Bao, L. C. Zhang, Q. Y. Yao, and Y. Lunn, "Estimating the peak indentation force of the edge chipping of rocks using single point-attack pick," Rock Mechanics and Rock Engineering, vol. 44, no. 3, pp. 339-347, 2011.

[9] H. X. Jiang, C. L. Du, S. Y. Liu, and K. D. Gao, "Numerical simulation of rock fragmentation process by roadheader pick," Journal of Vibroengineering, vol. 15, no. 4, pp. 1087-1817, 2013.

[10] S. Dewangan, S. Chattopadhyaya, and S. Hloch, "Critical damage analysis of WC-co tip of conical pick due to coal excavation in mines," Advances in Materials Science and Engineering, vol. 2015, Article ID 292046, 7 pages, 2015.

[11] S. Dewangan, S. Chattopadhyaya, and S. Hloch, "Wear assessment of conical pick used in coal cutting operation," Rock Mechanics and Rock Engineering, vol. 48, no. 5, pp. 2129-2139, 2015.

[12] R. Ciccu and B. Grosso, "Improvement of disc cutter performance by water-jet assistance," Rock Mechanics and Rock Engineering, vol. 47, no. 2, pp. 733-744, 2014.

[13] X. X. Liu, S. Y. Liu, and H. F. Ji, "Mechanism of rock breaking by pick assisted with water-jet of different modes," Journal of Mechanical Science and Technology, vol. 29, no. 12, pp. 53595368, 2015.

[14] J. R. Tang, Y. Y. Lu, Z. L. Ge, B. W. Xia, and J. H. Wang, "Combined drilling of hard rock with abrasive water-jet and mechanical bit to improve drilling efficiency," Journal of Mining and Safety Engineering, vol. 30, no. 4, pp. 621-627, 2013.

[15] H. X. Jiang, C. L. Du, S. Y. Liu, and K. D. Gao, "Numerical simulation of rock fragmentation under the impact load of water jet," Shock and Vibration, vol. 2014, Article ID 219489, 11 pages, 2014.

[16] L. Sitek, J. Foldyna, P. Martinec et al., "Use of pulsating water jet technology for removal of concrete in repair of concrete structures," Baltic Journal of Road and Bridge Engineering, vol. 6, no. 4, pp. 235-242, 2011.

[17] O. Fenn, "The use of water-jets to assist free-rolling cutters in the excavation of hard rock," Journal of the Southern African Institute of Mining and Metallurgy, vol. 87, no. 5, pp. 137-147, 1987.

[18] M. Hood, C. K. Geoffrey, and D. T. Edward, “A review of jet assisted rock cutting," Journal of Manufacturing Science and Engineering, vol. 144, no. 2, pp. 196-206, 1992.

[19] X. B. Li, D. A. Summers, G. Rupert, and P. Santi, "Experimental investigation on the breakage of hard rock by the PDC cutters with combined action modes," Tunnelling and Underground Space Technology, vol. 16, no. 2, pp. 107-114, 2001.

[20] R. Ciccu and B. Grosso, "Improvement of the excavation performance of PCD drag tools by water-jet assistance," Rock Mechanics and Rock Engineering, vol. 43, no. 4, pp. 465-474, 2010.

[21] Y. Y. Lu, J. R. Tang, Z. L. Ge, B. W. Xia, and Y. Liu, "Hard rock drilling technique with abrasive water-jet assistance," International Journal of Rock Mechanics and Mining Sciences, vol. 60, no. 2, pp. 47-56, 2013.

[22] S. Y. Liu, J. F. Chen, and X. H. Liu, "Rock breaking by conical pick assisted with high pressure water-jet," Advances in Mechanical Engineering, vol. 6, p. 868041, 2014. 
[23] S. Y. Liu, Z. H. Liu, X. X. Cui, and H. X. Jiang, "Rock breaking of conical cutter with assistance of front and rear water-jet," Tunnelling and Underground Space Technology, vol. 42, no. 5, pp. 78-86, 2014.

[24] Z. H. Liu, C. L. Du, Y. L. Zheng, Q. B. Zhang, and J. Zhao, "Effects of nozzle position and waterjet pressure on rockbreaking performance of roadheader," Tunnelling and Underground Space Technology, vol. 69, pp. 18-27, 2017.

[25] H. X. Jiang, C. L. Du, and K. H. Zheng, "Experimental research on the rock fragmentation load of a water-jet-assisted cutting head," Tehnicki Vjesnik-Technical Gazette, vol. 22, no. 5, pp. 1277-1285, 2015.

[26] H. X. Jiang, C. L. Du, and J. H. Dong, "Investigation of rock cutting dust formation and suppression using water-jets during mining," Powder Technology, vol. 307, pp. 99-108, 2017.

[27] K. G. Hurt and C. J. Morris, "Computer designed cutting heads improve roadheader performance," Tunnels and Tunnelling International, vol. 17, no. 3, pp. 37-38, 1985.

[28] O. Z. Hekimoglu and R. J. Fowell, "Theoretical and practical aspects of circumferential pick spacing on boom tunneling machine cutting heads," Mining Science and Technology, vol. 13, no. 3, pp. 257-270, 1991.

[29] E. M. Eyyuboglu and N. Bolukbasi, "Effects of circumferential pick spacing on boom type roadheader cutting head performance," Tunnelling and Underground Space Technology, vol. 20 , no. 5, pp. 418-425, 2005.

[30] B. Chiaia, "Fracture mechanisms induced in a brittle material by a hard cutting indenter," International Journal of Solids and Structures, vol. 38, no. 44-45, pp. 7747-7768, 2001.

[31] H. Liu, J. Wang, N. Kelson, and R. J. Brown, "A study of abrasive waterjet characteristics by CFD simulation," Journal of Materials Processing Technology, vol. 153-154, no. 1, pp. 488-493, 2004.

[32] X. P. Long, X. F. Ruan, Q. Liu, Z. W. Chen, S. X. Xue, and Z. Q. Wu, "Numerical investigation on the internal flow and the particle movement in the abrasive waterjet nozzle," Power Technology, vol. 314, no. 1, pp. 635-640, 2017.

[33] S. Y. Liu, X. X. Liu, J. F. Chen, and M. X. Lin, "Rock breaking performance of a pick assisted by high-pressure water-jet under different configuration modes," Chinese Journal of Mechanical Engineering, vol. 28, no. 3, pp. 607-617, 2015.

[34] H. X. Jiang, C. L. Du, S. Y. Liu, and K. D. Gao, "Theoretical modeling of rock breakage by hydraulic and mechanical tool," Mathematical Problems in Engineering, vol. 2014, Article ID 895835, 9 pages, 2014. 


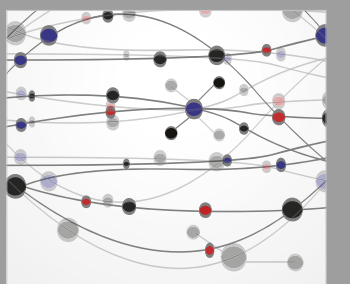

The Scientific World Journal
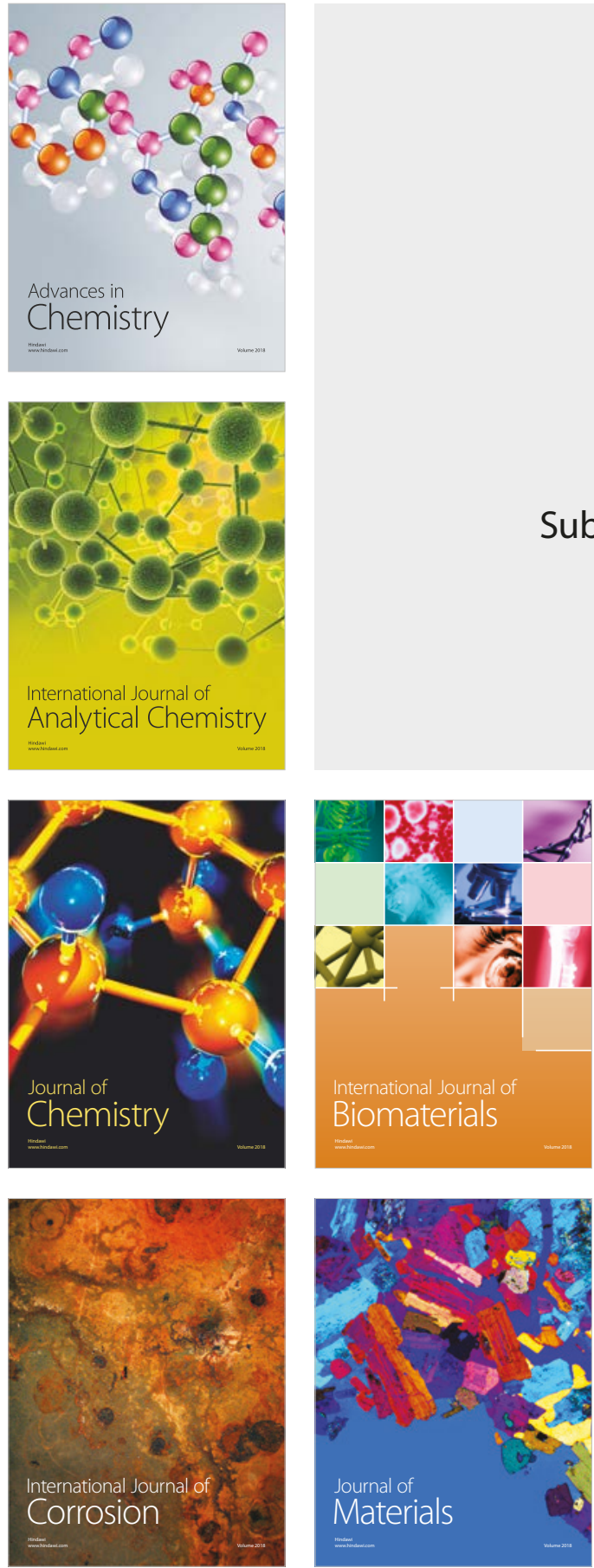

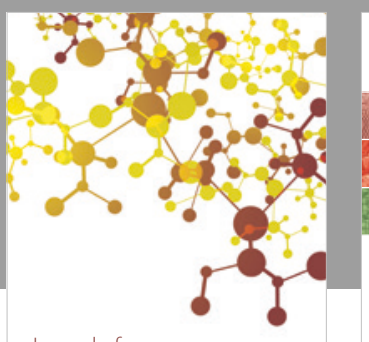

Journal of

Applied Chemistry
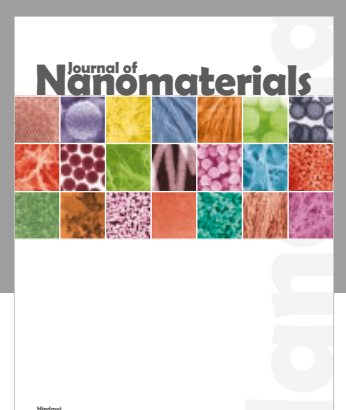



Scientifica



Polymer Science

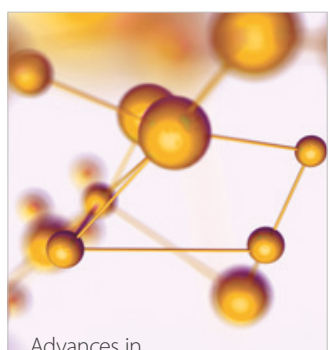

Physical Chemistry
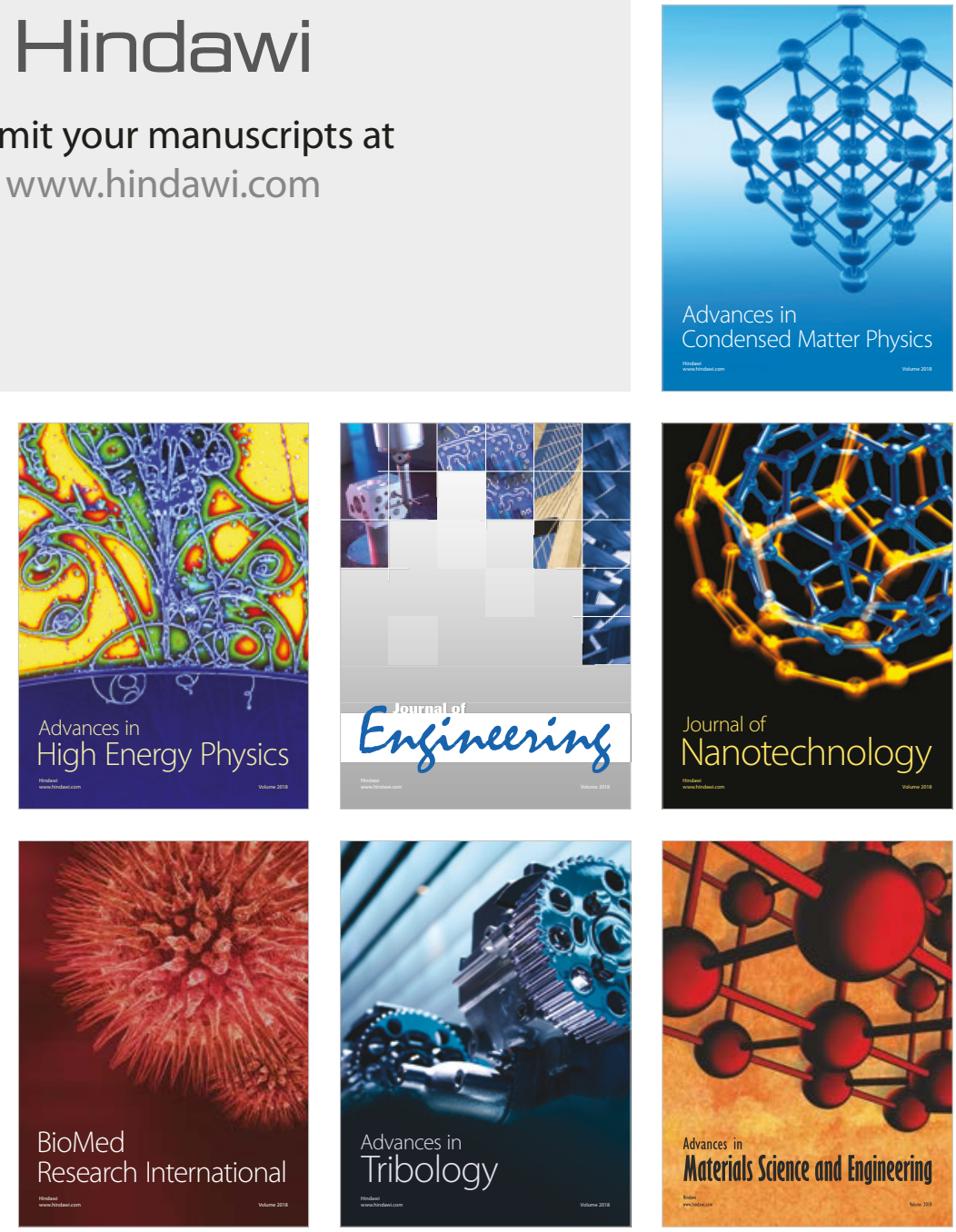